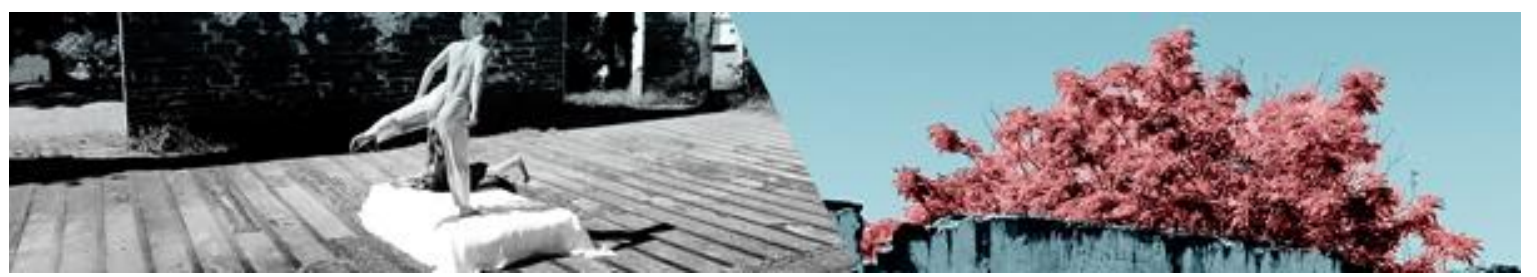

\title{
SISTEMA LABAN/BARTENIEFF DE ANÁLISE DE MOVIMENTO: GRANDES TEMAS - CAMINHOS PARA UMA PRÁTICA CRIATIVA DE DANÇA NA EDUCAÇÃO INFANTIL
}

Luísa Fedrizzi el Andari ${ }^{1}$

Resumo: Este estudo apresenta considerações a partir de propostas de trabalho com dança para crianças de quatro a seis anos, que se encontram na Educação Infantil. A temática principal destas propostas parte dos Grandes Temas do Sistema Laban/Bartenieff de Análise de Movimento. Verificam-se referenciais nacionais para a Educação Infantil; apresentam-se ideias de autores que refletem sobre a dança no contexto escolar; e são apontados possíveis caminhos para a prática criativa do Sistema Laban/Bartenieff com crianças dentro do contexto supracitado. As propostas são aplicadas e verificadas em duas escolas de educação infantil da cidade de Caxias do Sul - RS.

Palavras-chave: Dança-educação; Educação Infantil; Sistema Laban/Bartenieff de Análise de Movimento.

\section{LABAN/BARTENIEFF SYSTEM OF MOVEMENT ANALYSIS: GREAT THEMES - PATHS FOR A CREATIVE DANCE PRACTICE IN THE INFANT EDUCATION}

\begin{abstract}
This study presentes considerations about some proposals for dance teaching to four-tosix-year-old children in the Infant Education in Brazil. The main subject of these proposals is the Great Themes of the Laban/Bartenieff System of Movement Analysis. The National Infant Education Curriculum Framework is verified. Ideas from authors that reflect on dance in the school context are presented. Possible ways to a creative practice of the Laban/Bartenieff System of Movement Analysis with children are presented. The proposals are applied and verified in two Infant Education Schools in the city of Caxias do Sul (Rio Grande do Sul - Brazil).
\end{abstract}

Keywords: Educational dance; Childhood education; Laban/Bartenieff System of Movement Analysis.

\section{Introdução}

A Educação Infantil é uma etapa escolar de grande importância, visto que as experiências vividas nesta fase influenciam diretamente o desenvolvimento e a formação do ser humano. Atuando como professora de dança na educação infantil, há quatro anos, percebo o Sistema Laban/Bertenieff de Análise de Movimento (Sistema L/B) como um grande campo de pesquisa, investigação e contribuição para o trabalho criativo que desenvolvo com crianças no ambiente escolar.

\footnotetext{
${ }^{1}$ Luísa Fedrizzi el Andari - Formada no Curso Normal (Magistério) pelo Colégio São Carlos - Caxias do Sul/RS. Licenciada em Dança - graduação - pela ULBRA (Universidade Luterana do Brasil) Canoas/RS. Especialista em Sistema Laban/Bartenieff - pós-graduação - pela FAV (Faculdade Angel Vianna) - Rio de Janeiro/RJ.
}

ANDARI, Luísa Fedrizzi el. Sistema Laban/Bartenieff de análise de movimento: Grandes Temas Caminhos para uma Prática Criativa de Dança na Educação Infantil. Revista da FUNDARTE, Montenegro, p.529-544, ano 19, no 37, Janeiro/Março.

Disponível em: http://.seer.fundarte.rs.gov.br/index.php/RevistadaFundarte/index> 30 de março de 2019. 


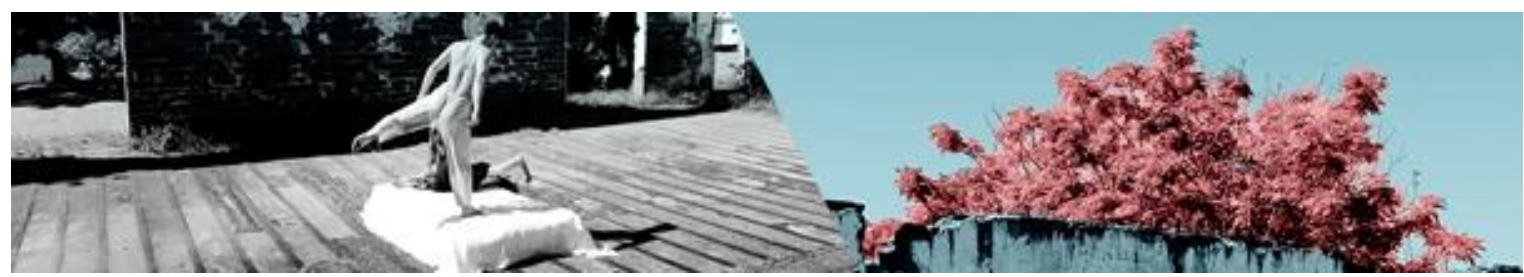

No presente estudo realizo uma reflexão crítica acerca de minha pesquisa realizada como trabalho de conclusão de curso $^{2}$ da pós-graduação em Sistema L/B, que trata de uma abordagem didática e metodológica desse Sistema em aulas de dança com crianças de quatro a seis anos no contexto escolar, com foco nos quatro Grandes Temas que envolvem todo o Sistema: Interno-Externo, Ação-Recuperação, Função-Expressão, Mobilidade-Estabilidade. Na referida monografia, foram apresentadas quatro propostas de trabalho (uma para cada Grande Tema), com duração de cinco, seis ou mais aulas cada, descrevendo, passo a passo, as atividades que foram trabalhadas com três turmas de crianças das idades citadas acima, duas da Escola de Educação Infantil ABC e uma da Escola de Educação Infantil Crescer (ambas localizadas na cidade de Caxias do Sul - RS). Neste artigo, faço uma reflexão pós-prática de todas essas atividades, e busco situar o leitor sobre a realidade brasileira do ensino da dança, apontando alguns suportes encontrados para meu trabalho. Assim, além da abordagem do próprio Sistema e da apresentação dos quatro Grandes Temas, considero no processo desta pesquisa os Referenciais Curriculares Nacionais (brasileiros) para a Educação Infantil, os Parâmetros Nacionais de Qualidade da Educação Infantil e a Base Nacional Comum Curricular, todos estes previstos pelo Ministério da Educação, além de reflexões de alguns autores acerca da prática docente da dança no contexto escolar.

Busco analisar criticamente a viabilidade e a importância do trabalho com os Grandes Temas do referido Sistema, abordando o movimento e a dança como um caminho de percepção acerca da relação entre o indivíduo, o outro e o espaço.

\section{O Sistema Laban/Bartenieff de Análise de Movimento}

O Sistema Laban/Bartenieff de Análise de Movimento (Sistema L/B), segundo Bartenieff (2002), proporciona um conhecimento aprofundado sobre o corpo em movimento. Ele pode ser abordado por questões didáticas e metodológicas a partir de quatro categorias que se modificam mutuamente e que nos permitem observar,

\footnotetext{
${ }^{2}$ AUTOR. Sistema Laban/Bartenieff de Análise de Movimento: Grandes temas - caminhos para uma prática criativa de dança na educação infantil. 2018. Trabalho de Conclusão de Curso (Especialização)-Faculdade de Dança Angel Vianna, Rio de Janeiro, 2018. 


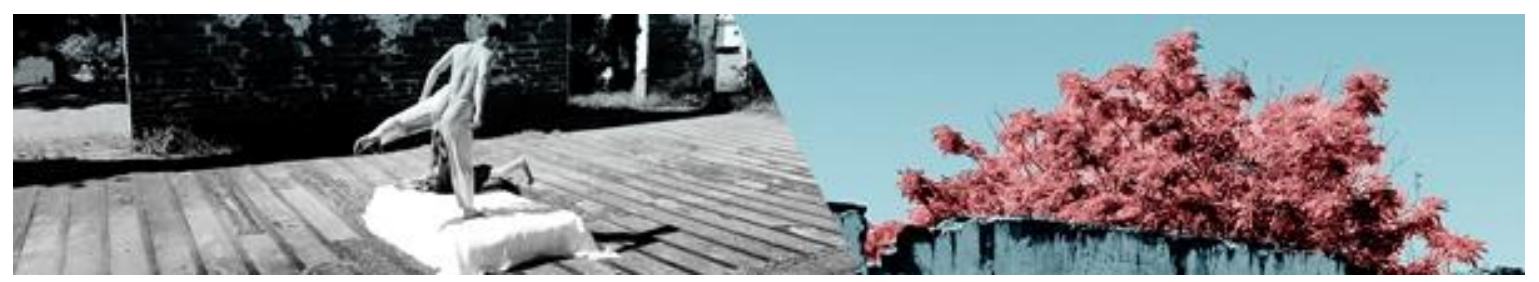

descrever, criar, experimentar, analisar e registrar o movimento humano. São elas: Corpo, Esforço, Forma e Espaço. Em inglês: Body, Effort, Shape, Space, (BESS).

O estudo do movimento a partir de cada categoria nos indica um caminho de respostas para as seguintes perguntas: o que se move = Categoria Corpo; como se move = Categoria Esforço; com quem se move = Categoria Forma; e onde se move = Categoria Espaço.

\section{Os Grandes Temas}

Existem quatro Grandes Temas que envolvem e permeiam todos os aspectos do Sistema Laban/Bartenieff (Sistema L/B). São eles: Interno/Externo, Ação/Recuperação, Função/Expressão e Mobilidade/Estabilidade. Não estão aqui apresentados em ordem de importância, visto que não há hierarquia entre eles.

Interno/Externo: Segundo Hackney (2002), são reflexos um do outro e estão sempre em uma relação criativa, o que proporciona coerência e significado ao movimento humano. Miranda (2008) acrescenta que o suporte do corpo não está dentro dele; ele existe a partir da troca permanente com o fora-dentro de si. Nas aulas para crianças, deseja-se que o aluno/dançarino esteja consciente de suas sensações enquanto interage com o meio. Conforme Fernandes (2006), "é a partir deste diálogo Interno/Externo que ocorre o aprendizado corporal".

Para o trabalho em dança, com enfoque nesse tema, algumas perguntas podem auxiliar no trato com alunos, como sugestão de Hackney (2002): "Como esse movimento que você vem fazendo é dentro de você? Que significado ele tem para você? Quando você ouve a palavra interno ou a palavra externo, o que vem à mente?"

Ação/Recuperação: Outro grande tema trata dos conceitos e das relações entre Ação/Recuperação, o qual "refere-se ao processo ou tendência natural de recuperar-se de alguma atividade através de qualidades complementares ou diferentes, estabelecendo um ritmo de equilíbrio no corpo" (FERNANDES, 2006, p. 266).

Cox e Studd (2013) lembram que Ação e Recuperação são relativas e diferentes para cada um, pois aquilo que é a Recuperação para uma pessoa pode ANDARI, Luísa Fedrizzi el. Sistema Laban/Bartenieff de análise de movimento: Grandes Temas Caminhos para uma Prática Criativa de Dança na Educação Infantil. Revista da FUNDARTE, Montenegro, p.529-544, ano 19, no 37, Janeiro/Março.

Disponível em: http://.seer.fundarte.rs.gov.br/index.php/RevistadaFundarte/index> 30 de março de 2019. 


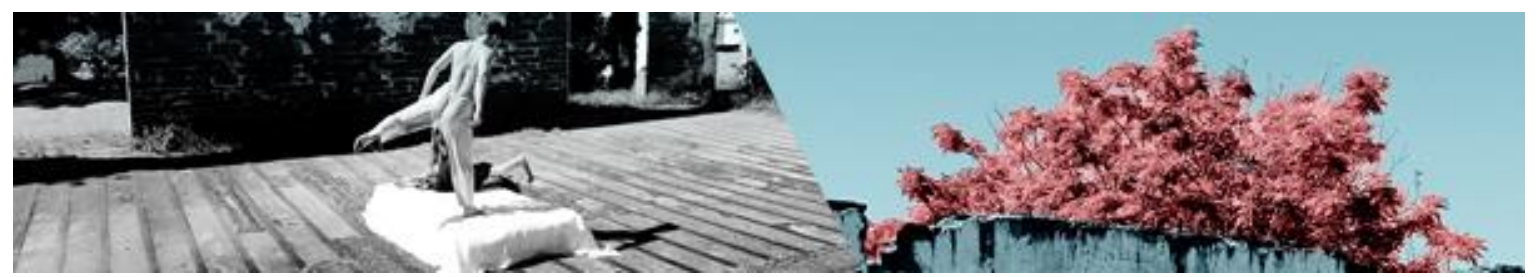

não ser para outra. Independente de qual movimento seja a Ação e qual seja a Recuperação, Hackney (2002) afirma que uma seguida pela outra é um ciclo natural do corpo, para que o mesmo possa se reabastecer e para manter a vitalidade do movimento.

Função/Expressão: Cox e Studd (2013) contextualizam a Função como o lado anatômico do movimento (que inclusive pode ser analisado cientificamente), estando relacionada ao "que" se move. Já a Expressão trata mais do "como" e do "por que" o movimento acontece. Fernandes (2006) aponta que "a expressividade e a funcionalidade estão em constante relação". É interessante que o professor/mediador tenha a consciência de que, ao aprimorar a função de um membro do corpo, como, por exemplo, fortificando a musculatura, consequentemente poderá melhorar também a expressão deste membro em movimento. Da mesma forma, enfatizar a expressão em determinada movimentação pode aperfeiçoar aspectos relativos à função.

Miranda (2008) aponta que há uma necessidade de vida (expressão) em todos os movimentos, até mesmo nas ações cotidianas conhecidas como funcionais (caminhar, sentar, levantar), o que vai ao encontro da afirmação de Bartenieff apud Hackney (2002), de que corpo não é um símbolo de expressão, mas sim a própria expressão. Conforme sugestão de Hackney (2002), algumas perguntas podem auxiliar no trabalho com alunos. "De que se trata esse movimento para você? Como a função está lhe ajudando a se expressar no mundo? Como a expressão está realmente funcionando para você?"

Mobilidade/Estabilidade: São opostos que se complementam, pois "todo movimento contém os dois conceitos, Mobilidade e Estabilidade, um tornando o outro possível." (FERNANDES, 2006, p. 268). É importante frisar que estabilidade não significa falta de movimento, porque mesmo o conceito de "ficar parado" é dinâmico. Este tema, segundo Fernandes (2006) está ligado aos conceitos de fluxo contido e fluxo livre, pois nos remete a questões como: "Quando ficar parado? Quando mover-se?". Cox e Studd (2013) exemplificam esta relação: se uma pessoa está com medo de cair, normalmente ela contém o fluxo. Porém, isso aumenta as chances de ela cair, pois não fica com o corpo disponível para se acomodar às mudanças de peso e de espaço que talvez sejam necessárias para o momento. ANDARI, Luísa Fedrizzi el. Sistema Laban/Bartenieff de análise de movimento: Grandes Temas Caminhos para uma Prática Criativa de Dança na Educação Infantil. Revista da FUNDARTE, Montenegro, p.529-544, ano 19, ํo 37, Janeiro/Março.

Disponível em: http://.seer.fundarte.rs.gov.br/index.php/RevistadaFundarte/index> 30 de março de 2019. 


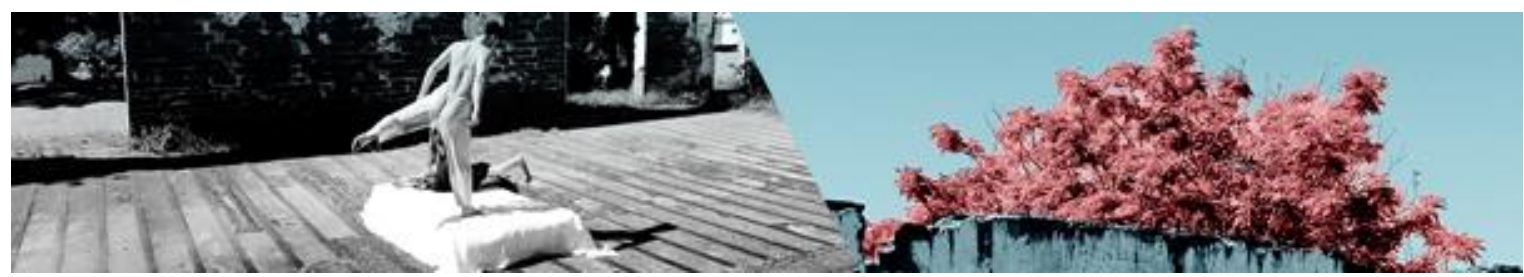

A dualidade entre mobilidade e estabilidade trata de oscilações, "onde a estabilidade é percebida como estabilidade móvel, uma frequência mais calma, que refreia a mobilidade enlouquecida". (MIRANDA, 2008, p. 42). Hackney (2002) traz como exemplo um ditado popular que fala que há dois presentes que precisamos dar às crianças: raízes e asas. A autora afirma que é necessário focar nos elementos de estabilidade e mobilidade e, principalmente, na relação entre eles. Pois abordar a estabilidade faz com que a mobilidade se torne mais disponível, visto que um senso de enraizamento promove segurança e sensação de liberdade, já que há suporte.

\section{A Dança na Escola de Educação Infantil: Contexto Brasileiro}

A inclusão da dança na disciplina de Arte no Brasil vem sendo um desafio para os profissionais da área de Licenciatura em Dança que estão ingressando nas escolas. Na Educação Infantil, a dança é comumente trabalhada como uma brincadeira ou uma atividade física pelos próprios professores de sala de aula. Marques (2012) comenta que, historicamente no Brasil, a área da dança é marcada pela falta de profissionais qualificados para ensiná-la e, como consequência, frequentemente deixada a cargo de professores com outras formações, como Pedagogia, Educação Física ou Arte, que em sua maioria não tem a experiência ou a reflexão pedagógica sobre as especificidades da dança.

No Brasil, existe um documento norteador para o trabalho com a Educação Infantil, chamado de Referencial Curricular Nacional para a Educação Infantil ${ }^{3}$ (abreviado pela sigla RCNEI), escrito em 1998. Este documento apresenta um conjunto de reflexões acerca do contexto educacional, para crianças de zero a seis anos, traçando objetivos, conteúdos e orientações didáticas para os educadores. Analisando o RCNEl (1998), percebe-se que não está previsto especificamente o ensino da dança para as crianças da maneira como estão previstas a música e as artes visuais. Porém, os capítulos que tratam sobre o movimento e a expressividade das crianças aborda a dança como uma das maneiras de desenvolvê-lo.

\footnotetext{
${ }^{3} \mathrm{O}$ documento pode ser consultado através do link: http://portal.mec.gov.br/seb/arquivos/pdf/volume3.pdf ANDARI, Luísa Fedrizzi el. Sistema Laban/Bartenieff de análise de movimento: Grandes Temas Caminhos para uma Prática Criativa de Dança na Educação Infantil. Revista da FUNDARTE, Montenegro, p.529-544, ano 19, no 37, Janeiro/Março.

Disponível em: http://.seer.fundarte.rs.gov.br/index.php/RevistadaFundarte/index> 30 de março de 2019.
} 


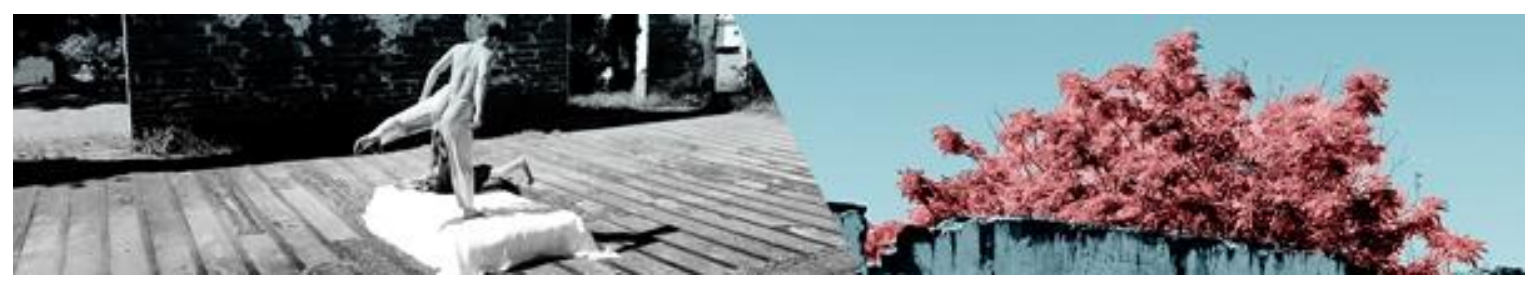

O documento, que é norteador para o trabalho com Educação Infantil em todo o Brasil, apresenta um capítulo inteiro dedicado ao movimento da criança. Em contradição, a dança não é conteúdo obrigatório. E, quando a dança aparece como uma sugestão ou possibilidade, não há menção sobre qualquer exigência de um profissional especializado, graduado em Licenciatura em Dança. Percebe-se que o que se solicita que os professores de educação infantil, formados em pedagogia, trabalhem com os alunos em termos de movimento, poderia ser mais eficaz e melhor trabalhado por um profissional com capacitação específica da área da dança. O ensino especializado da dança nas escolas de educação infantil, sob coordenação de um profissional da área, é subentendido como serviço opcional, e as escolas que oferecem essa atividade a apresentam como um diferencial.

Para as crianças de 4 a 6 anos, são traçados pelos RCNEl alguns objetivos para o desenvolvimento do movimento. São eles:

Ampliar as possibilidades expressivas do próprio movimento, utilizando gestos diversos e o ritmo corporal nas suas brincadeiras, danças, jogos e demais situações de interação; explorar diferentes qualidades e dinâmicas do movimento, como força, velocidade, resistência e flexibilidade, conhecendo gradativamente os limites e as potencialidades de seu corpo; controlar gradualmente o próprio movimento, aperfeiçoando seus recursos de deslocamento e ajustando suas habilidades motoras para utilização em jogos, brincadeiras, danças e demais situações; utilizar os movimentos de preensão, encaixe, lançamento etc., para ampliar suas possibilidades de manuseio dos diferentes materiais e objetos; apropriar-se progressivamente da imagem global de seu corpo, conhecendo e identificando seus segmentos e elementos e desenvolvendo cada vez mais uma atitude de interesse e cuidado com o próprio corpo. (RCNEI, 1998, P 27).

Ao analisá-los, impossível não relacioná-los com os conteúdos do Sistema Laban/Bartenieff, pois suas temáticas contemplariam os objetivos desejados. $O$ trabalho realizado por um profissional específico da dança vai ao encontro da afirmação encontrada nos RCNEI:

[...] é possível criar, intencionalmente, oportunidades para que as crianças se apropriem dos significados expressivos do movimento. A dimensão expressiva do movimento engloba tanto as expressões e comunicação de ideias, sensações e sentimentos pessoais como as manifestações corporais que estão relacionadas com a cultura. A dança é uma das manifestações da cultura corporal dos diferentes

ANDARI, Luísa Fedrizzi el. Sistema Laban/Bartenieff de análise de movimento: Grandes Temas Caminhos para uma Prática Criativa de Dança na Educação Infantil. Revista da FUNDARTE, Montenegro, p.529-544, ano 19, no 37, Janeiro/Março.

Disponível em: http://.seer.fundarte.rs.gov.br/index.php/RevistadaFundarte/index> 30 de março de 2019. 


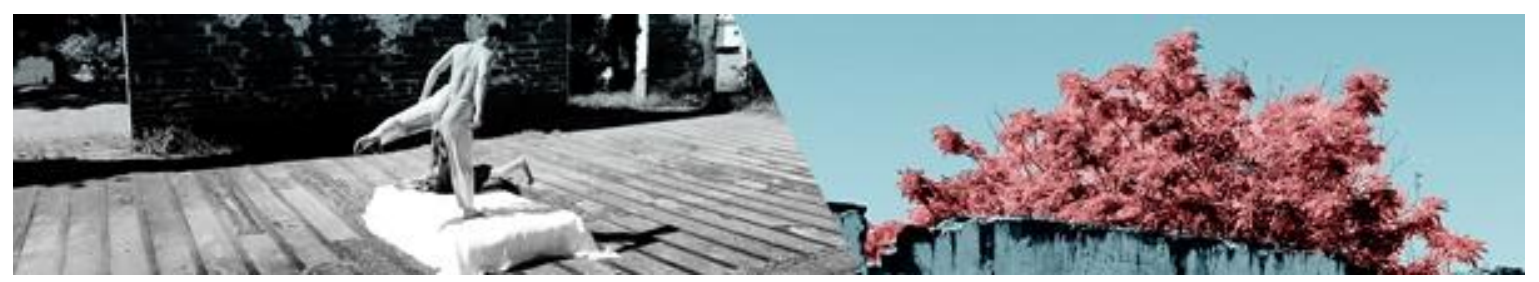

grupos sociais que está intimamente associada ao desenvolvimento das capacidades expressivas das crianças. (RCNEI, 1998, p. 30).

Assim, entendo que é interessante que o trabalho com dança não aconteça somente através da cópia e repetição. Ao contrário, deve proporcionar momentos de exploração e descoberta, com improvisações direcionadas, concordando com o que preveem os Referenciais: "A aprendizagem da dança pelas crianças, porém, não pode estar determinada pela marcação e definição de coreografias pelos adultos." (RCNEI, 1998, p. 30)

Também há no Brasil, lançados recentemente - em 2018 - outros dois documentos norteadores: a Base Nacional Comum Curricular ${ }^{4}$ e os Parâmetros Nacionais de Qualidade da Educação Infantil ${ }^{5}$. Na Base Nacional Comum Curricular (Ministério da Educação, 2018) são abordados como um campo: o corpo, os gestos e o movimento, apresentando o fato de que as crianças exploram o mundo, o espaço e os objetos, formam relações, expressam seus sentimentos, produzem conhecimento sobre si e o mundo, através do corpo. O documento aponta, ainda, a dança como uma das maneiras de entrelaçar corpo, emoção e linguagem. Os Parâmetros Nacionais de Qualidade da Educação Infantil estão divididos em áreas focais. A área focal 4 - Currículos, Interações e Práticas Pedagógicas - está subdividida em princípios, sendo que um deles é chamado de Qualidade das Interações. Dentro deste princípio são apontados parâmetros para o professor. Destaco o parâmetro 4.2.12: "Possibilitar que crianças expressem seus sentimentos e pensamentos e possam fazer uso de diferentes linguagens para se expressar" (Ministério da Educação, 2018, p. 50). Encontro, a partir destes dois documentos acima citados, um suporte para validar a importância do trabalho da dança na educação infantil, entendendo que o movimento e a dança são formas de linguagem e vias diretas para a expressão de sentimentos e pensamentos.

\section{A Dança na Escola: Reflexões}

\footnotetext{
${ }^{4} \mathrm{O}$ documento pode ser consultado através do link: http://basenacionalcomum.mec.gov.br/

$5 \mathrm{O}$ documento pode ser consultado através do link: https://undime.org.br/uploads/documentos/phpL4cLyK_5c3e0fd376fd9.pdf

ANDARI, Luísa Fedrizzi el. Sistema Laban/Bartenieff de análise de movimento: Grandes Temas Caminhos para uma Prática Criativa de Dança na Educação Infantil. Revista da FUNDARTE, Montenegro, p.529-544, ano 19, no 37, Janeiro/Março.

Disponível em: http://.seer.fundarte.rs.gov.br/index.php/RevistadaFundarte/index> 30 de março de 2019.
} 


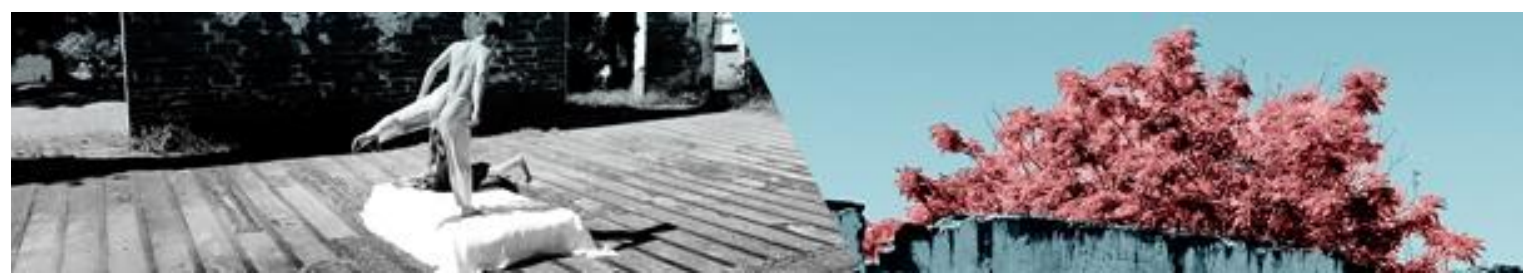

O movimento é essencial quando se diz respeito ao universo infantil. Ossona (1998) comenta que mover-se está associado à inteligência e aos sentimentos, assim como com a capacidade de estabelecer comunicação e conexões. Por isso a exploração de movimentos aumenta o potencial expressivo do ser humano.

De acordo com Laban (1985 apud MARQUES, 2001), a criança e o adolescente precisam ter a oportunidade de expressar suas subjetividades enquanto corpos que dançam, experimentam exploram e se conhecem. Neves (2006) afirma que a dança contribui para a criação e ampliação do vocabulário pessoal de movimento do aluno, assim como para a criação da identidade, valorizando e respeitando as individualidades. Pois "cada um deve acreditar ser uma pessoa que é dançarina, e não um dançarino que é uma pessoa" (FERREIRA, 2008, p. 108). Reconhece-se que todo ser humano carrega consigo uma vasta experiência, independente do seu tempo de vida; ignorar este conhecimento que vem agregado ao corpo é transformar a dança em algo impessoal. Bertazzo (2014) concorda, pois afirma que mesmo em exercícios de movimentos orientados, manifestam-se as histórias individuais de cada corpo. Valorizar as bagagens de cada um, mesmo que para isso surjam múltiplas diferenças, é enriquecer o ensino e formar cidadãos criativos, sensíveis e conscientes.

Quanto à postura do professor, Marques (2001) afirma que o educador que atua como mediador, e não como transmissor/detentor do conhecimento, proporciona ao educando uma compreensão mais abrangente do que é dançar. Identifico, portanto, que manter os alunos motivados, conscientes e descobridores, desde cedo, de suas próprias limitações e possibilidades é um dos mais importantes papéis do professor de dança da educação infantil, e o trabalho com o Sistema Laban/Bartenieff pode ajudar nesse processo.

\section{Análise Crítica: Reflexões pós-prática docente de dança com crianças de quatro a seis anos, a partir dos Grandes Temas}

Foram realizadas, durante o primeiro semestre de 2018, práticas de dança embasadas nos Grandes Temas do Sistema Laban/Bartenieff de Análise de Movimento em duas escolas da cidade de Caxias do Sul - RS - Brasil: Escola de ANDARI, Luísa Fedrizzi el. Sistema Laban/Bartenieff de análise de movimento: Grandes Temas Caminhos para uma Prática Criativa de Dança na Educação Infantil. Revista da FUNDARTE, Montenegro, p.529-544, ano 19, ํo 37, Janeiro/Março.

Disponível em: http://.seer.fundarte.rs.gov.br/index.php/RevistadaFundarte/index> 30 de março de 2019. 


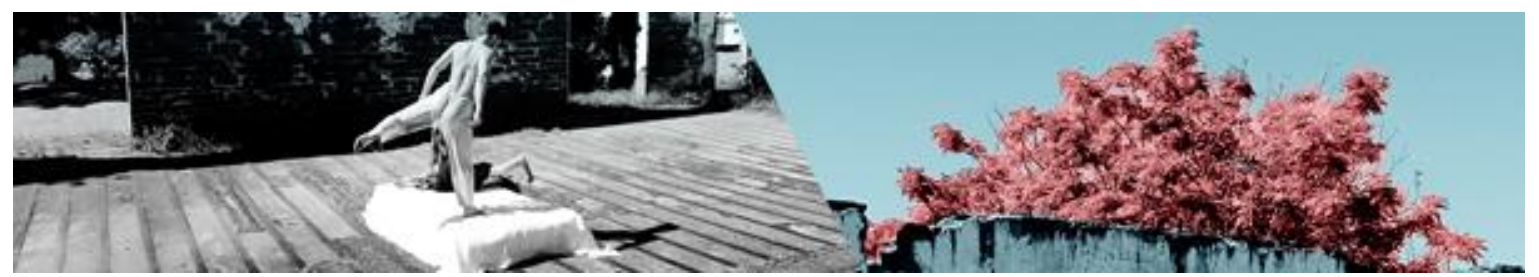

Educação Infantil ABC e Escola de Educação Infantil Crescer, com autorização das direções de ambas as escolas.

Interno/Externo: Esta proposta teve como base a exploração de dois objetos diferentes: a pena e a pedra, como estímulos para a compreensão do conceito de Interno-Externo. Foram objetivos desta proposta: explorar o movimento corporal, tendo como estímulo inicial a pedra e a pena como objetos e o conceito de InternoExterno como suporte teórico; e perceber a relação contínua de trocas entre InternoExterno.

As aulas passaram pelas seguintes etapas: sentindo na pele o peso da pena e o peso da pedra; observando a pena e a pedra com a intervenção do sopro e representando em movimento; observando a queda do objeto ao chão e representando em movimento; e investigando o movimento corporal a partir dos objetos pena e pedra.

Destaco que as trocas entre Interno e Externo acontecem todo o tempo nas aulas de dança com as crianças. Com o trabalho realizado, o que mudou foi a compreensão e a consciência das crianças de que estes aspectos existem e fazem parte de suas vidas. Como exemplo, apresento o relato de um aluno que percebeu que, no parquinho, quando um colega começava a se movimentar como pedra (objeto associado durante as atividades da aula de dança com peso forte, espaço direto e tempo rápido), parecia que ele e todos ficavam mais agitados, acordados e acelerados. Mas quando acabava o recreio e a professora começava a respirar e caminhar como uma pena (objeto associado durante as aulas com o peso leve, espaço indireto e tempo lento), chamando-os, ele já ia aos poucos se acalmando, e achava que os colegas também. Ou seja, houve a percepção de que um estímulo externo afetava não só a sua dinâmica interna como a dos colegas. E vice-versa.

Ação/Recuperação: Esta proposta teve como base a exploração de diferentes animais: girafa, tigre, tartaruga, lebre, bicho-preguiça, formiga, elefante e pulga, como estímulos para a compreensão do conceito de Ação/Recuperação. Foram objetivos: experimentar movimentações que se complementam em um ciclo de ação-recuperação, inspiradas em imagens de animais; e perceber a importância da realização de atividades contrastantes, porém complementares, para manter a vitalidade e a energia nos movimentos.

ANDARI, Luísa Fedrizzi el. Sistema Laban/Bartenieff de análise de movimento: Grandes Temas Caminhos para uma Prática Criativa de Dança na Educação Infantil. Revista da FUNDARTE, Montenegro, p.529-544, ano 19, n 37, Janeiro/Março.

Disponível em: http://.seer.fundarte.rs.gov.br/index.php/RevistadaFundarte/index> 30 de março de 2019. 


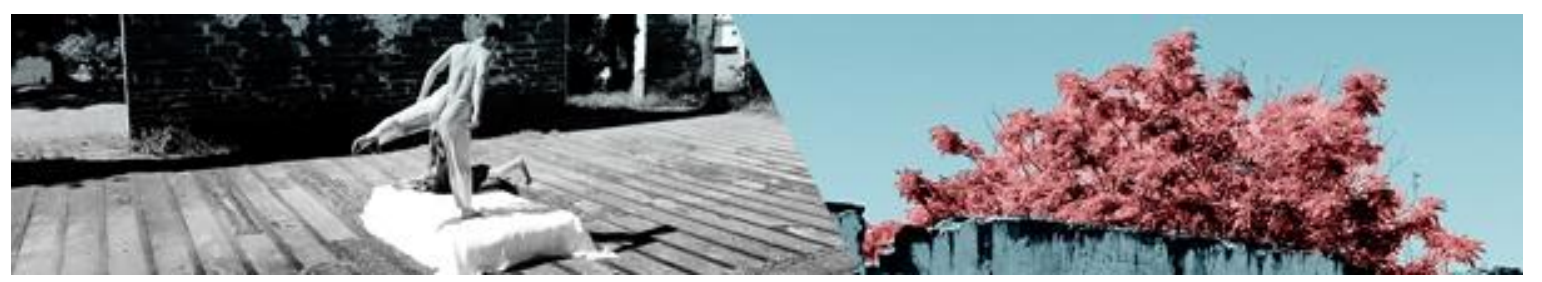

As aulas passaram pelas seguintes etapas: conhecendo a girafa e o tigre; relembrando e explorando a girafa e o tigre; conhecendo outros animais; explorando os animais; criando novos animais; improvisando a partir dos animais. Foram utilizadas imagens impressas e vídeos dos animais para auxiliar na compreensão.

Aqui também cabe um destaque: analisando as colocações das crianças, percebi que, por mais que não usassem exatamente a nomenclatura de AçãoRecuperação, elas estavam sentindo este ciclo no corpo e compreendendo a sua importância. Observei que isso as mantinha mais tempo em movimento e engajadas na atividade. Reflito que o ciclo de Ação-Recuperação não estava acontecendo somente no sentido de manter os seus corpos ativos e disponíveis para o movimento, mas também tinha um papel muito importante de manutenção da atenção e do engajamento interno das crianças, que ao se recuperarem constantemente, não apresentavam dispersão (o que é muito comum nesta idade, em atividades muito repetitivas).

Função/Expressão: Esta proposta teve como base a execução de tarefas relacionadas a desenhos do corpo no espaço e mapas de movimento como estímulos para a compreensão e exploração do conceito de Função/Expressão. Foram objetivos: relacionar a função de movimento, a partir do desenho no papel, com suas habilidades expressivas; e perceber que funcionalidade e expressividade estão em constante relação.

As aulas passaram pelas seguintes etapas: movimentando o corpo a partir da letra do nome; explorando o desenho da letra com o corpo; criando o mapa de movimento; adicionando expressão ao mapa de movimento; e explorando os mapas de movimento. As aulas contaram com folhas de papel e giz de cera.

O destaque, nesse caso, é que, durante as práticas nas escolas de educação infantil $A B C$ e Crescer, foi possível identificar que a Expressão faz parte do dia a dia das crianças. Mas às vezes, por estarem concentradas na Função (preocupação com as habilidades funcionais do corpo), acabavam contendo as suas expressividades. Da mesma forma, ao adicionarem Expressão, algumas vezes se perdiam na tarefa que estava sendo realizada. O grande desafio foi auxiliá-las a encontrar um equilíbrio. Percebo que este se encontra justamente na transição entre Função e Expressão, uma dando suporte para outra. É interessante que seja dado ANDARI, Luísa Fedrizzi el. Sistema Laban/Bartenieff de análise de movimento: Grandes Temas Caminhos para uma Prática Criativa de Dança na Educação Infantil. Revista da FUNDARTE, Montenegro, p.529-544, ano 19, no 37, Janeiro/Março.

Disponível em: http://.seer.fundarte.rs.gov.br/index.php/RevistadaFundarte/index> 30 de março de 2019. 


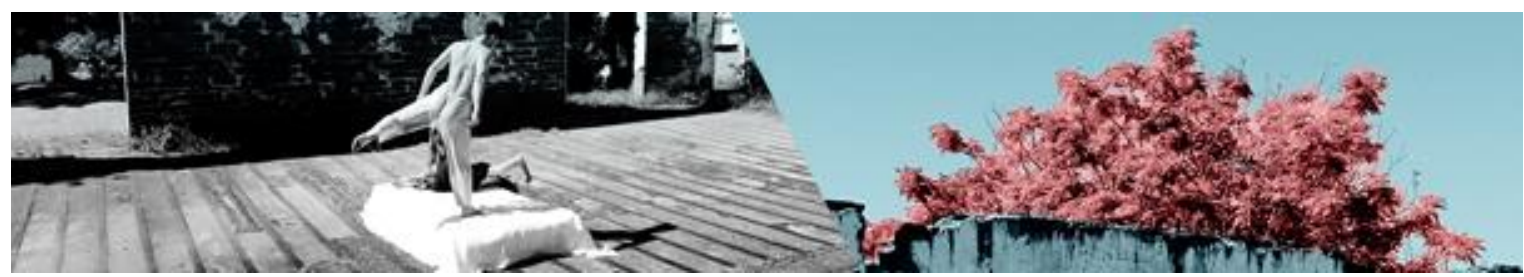

um tempo significativo para a prática de movimentos, para que as crianças fiquem seguras e tenham tempo para treinamento das habilidades funcionais necessárias e então possam desprender-se e adicionar Expressão.

Mobilidade Estabilidade: Esta proposta teve como base a exploração de alguns dos Padrões Neurocinesiológicos de Desenvolvimento ${ }^{6}$ (categoria Corpo) relacionados a animais, como estímulos para a compreensão do conceito de Mobilidade/Estabilidade. Foram objetivos: experimentar a Estabilidade como um suporte para a Mobilidade, construindo um senso de enraizamento que proporcione a liberdade de movimentação; bem como perceber a relação entre Mobilidade e Estabilidade, reconhecendo que uma complementa e potencializa a outra.

As aulas passaram pelas seguintes etapas: conhecendo o Padrão Homólogo (divisão parte superior/parte inferior); conhecendo o Padrão Homolateral (divisão lado direito/lado esquerdo); conhecendo o Padrão Contralateral (cruzado); explorando os três Padrões trabalhados; e utilizando jogos a partir dos conceitos estudados. Foram utilizadas fitas coloridas amarradas nos corpos das crianças para auxiliar na compreensão.

Aqui destaco que, quanto ao tema Mobilidade-Estabilidade, a consciência de movimento e de corpo gerada através das atividades possibilitou que enxergassem seus corpos como ferramentas com duas habilidades complementares: uma para mover-se e outra para estabilizar-se. As atividades exploradas ajudaram as crianças a tornarem-se capazes de separar seus corpos em partes para usá-las como um todo, mantendo relações onde uma parte é suporte de outra, e vice-versa. Percebi meus alunos envolvidos na experimentação, e ouso dizer que a exploração deste tema foi a que mais Ihes trouxe a consciência de que estavam tendo descobertas individuais, pois mostraram-se, em outros momentos após estas aulas, mais cientes de suas limitações e de suas possibilidades; assim como mais estimulados a

\footnotetext{
${ }^{6}$ É possível observar uma relação entre o desenvolvimento do ser humano e a evolução das espécies, ou seja, uma relação entre ontogênese e filogênese. Aspectos do movimento que estão presentes nos animais, partindo de um organismo unicelular (como a ameba), para um peixe, um anfíbio, um réptil até o mamífero se assemelham a aspectos do movimento do ser humano durante o seu desenvolvimento, sendo que "durante seus primeiros anos de vida, a criança move-se de uma forma gradualmente mais complexa, organizando os padrões motores e estabelecendo a estrutura de seu sistema neuromuscular" (FERNANDES, 2006, p. 56).
}

ANDARI, Luísa Fedrizzi el. Sistema Laban/Bartenieff de análise de movimento: Grandes Temas Caminhos para uma Prática Criativa de Dança na Educação Infantil. Revista da FUNDARTE, Montenegro, p.529-544, ano 19, no 37, Janeiro/Março.

Disponível em: http://.seer.fundarte.rs.gov.br/index.php/RevistadaFundarte/index> 30 de março de 2019. 


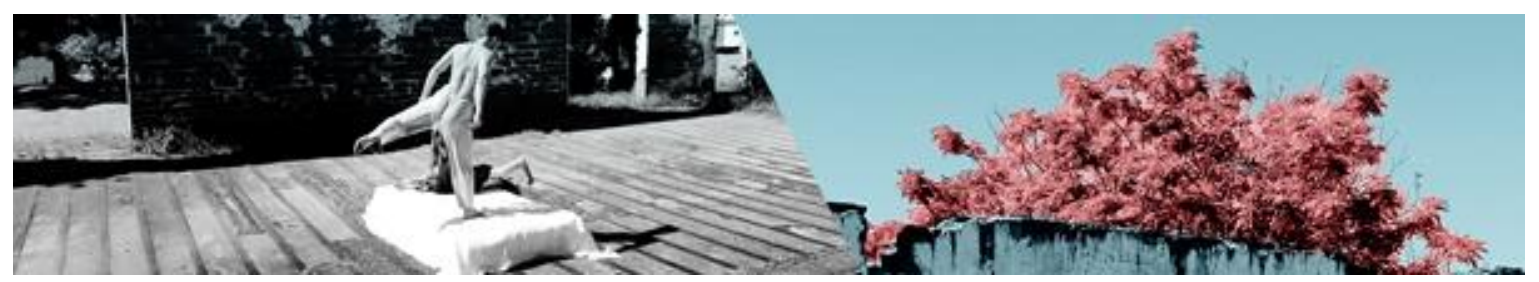

desenvolverem por caminhos próprios as habilidades de equilíbrio, movimento e demais desafios corporais através do jogo (que para eles é pura diversão!) que alterna entre onde sentir-se móvel e onde sentir-se estável.

\section{Considerações finais}

A dança possui papéis educacionais fortíssimos. Como educadores, precisamos saber aproveitá-la como ferramenta para formar cidadãos criativos, sensíveis e conscientes sobre si mesmo e sobre os outros. Penso que esse é o ponto chave da dança-educação: ser uma área de conhecimento que dá ferramentas aos alunos para aprimorarem aspectos sociais, cognitivos, emocionais, físicos e pessoais. Reconheço a importância de nós, profissionais da dança voltados ao contexto escolar, lutarmos constantemente para a validação do nosso trabalho, conectando aquilo que acreditamos com materiais de referência ao ensino, como experimentei fazer ao citar os documentos nacionais publicados pelo Ministério da Educação e ao relacioná-los com meu trabalho.

Encontro no Sistema Laban/Bartenieff de Análise de Movimento um grande suporte para realizar minha função de educadora da área de Dança/Arte na Educação Infantil. Como um pilar forte que sustenta uma construção de vários andares, percebo que este Sistema vem sendo a base sólida para ideias criativas e fundamentais do meu trabalho com dança.

Destaco como aspecto indispensável para o bom rendimento das aulas a presença da ludicidade; isso facilita o processo de aprendizagem e aumenta 0 interesse das crianças. É interessante observar que a ludicidade está intimamente relacionada ao tema Função-Expressão, pois é uma ferramenta para dar cor, emoção e expressão às atividades funcionais que são também fundamentais para o desenvolvimento do ser humano.

A abordagem criativa dos Grandes Temas do Sistema Laban/Bartenieff de Análise de Movimento, trazendo conceitos pertencentes às quatro categorias (Corpo, Esforço, Forma e Espaço) é viável e de grande importância, proporcionando benefícios aos alunos. Afinal, a contribuição acontece na medida em que a criança experimenta, através do movimento, a exploração do corpo, do espaço e da relação 


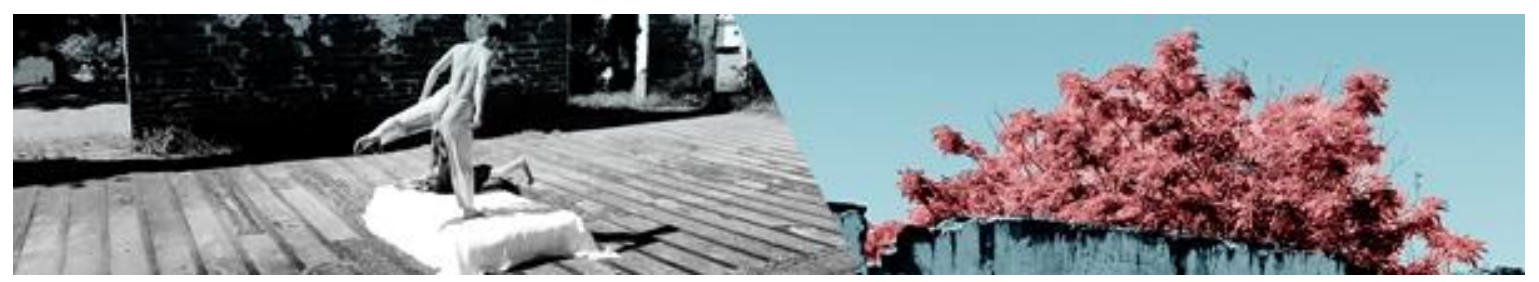

com o outro, ou seja, na medida em que o movimento se relaciona diretamente com aspectos expressivos nos âmbitos emocional, cognitivo e afetivo.

O Sistema Laban/Bartenieff de Análise de Movimento é uma ferramenta interessante e de muito potencial para desmistificar algumas questões do ambiente escolar, e para transformar as classificações de "bom" e "ruim" em "modos diferentes de ser". Quando a criança experimenta no corpo uma maneira diferente de se movimentar, a transformação acontece. Ela passa a entender que há outros padrões e a ter a opção de ser diferente, e também compreende o outro, que não é igual a si. Não quer dizer que precise ou que vá desejar mudar, mas conhece a possibilidade de fazê-lo. Isso é transformador; ouso dizer que não só para o próprio indivíduo, mas para toda a sociedade da qual ele faz e fará parte.

Identifico que, com crianças de quatro a seis anos, não é necessário trabalhar com a nomenclatura do Sistema Laban/Bartenieff de Análise de Movimento para alcançar os objetivos propostos, apesar de ter também percebido que é possível fazê-lo.

Os Grandes Temas do Sistema estão presentes não só intencionalmente nas aulas de dança, como também naturalmente na vida. As trocas existentes entre o Interno o Externo, o jogo constante entre Estabilidade e Mobilidade, o ciclo interminável de Ação e Recuperação, a íntima relação entre Função e Expressão fazem parte do dia a dia das crianças da Educação Infantil. Elas também fazem parte da relação entre o professor, o seu planejamento e os alunos. As trocas constantes entre Interno e Externo possibilitam sentir a fluidez ou não das atividades, assim como permitem avaliar a apreensão dos conteúdos por parte dos alunos e a sensação do próprio professor a partir da aula que está ministrando. $O$ jogo entre Ação e Recuperação permite o bom andamento das aulas, e isto vai além da manutenção da energia das crianças, uma vez que a variação e originalidade no planejamento também revitaliza o educador na sua tarefa de mediar conhecimentos.

A transição constante entre a Mobilidade e a Estabilidade pode ser pensada como a dualidade entre manter uma rotina (que é importantíssima para as crianças de quatro a seis anos) bem como trazer mudanças, novos olhares e mobilizar os alunos rumo a novos conhecimentos. O foco constante dos educadores em desenvolver habilidades funcionais necessárias a essa etapa do desenvolvimento ANDARI, Luísa Fedrizzi el. Sistema Laban/Bartenieff de análise de movimento: Grandes Temas Caminhos para uma Prática Criativa de Dança na Educação Infantil. Revista da FUNDARTE, Montenegro, p.529-544, ano 19, no 37, Janeiro/Março.

Disponível em: http://.seer.fundarte.rs.gov.br/index.php/RevistadaFundarte/index> 30 de março de 2019. 


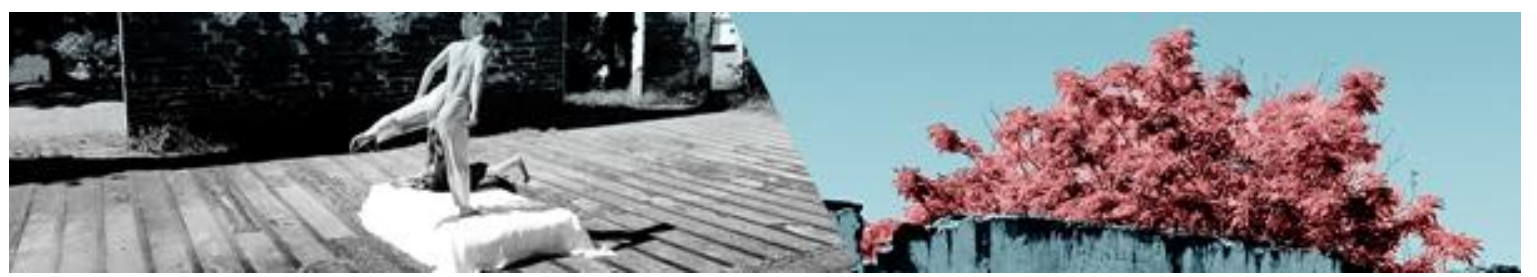

infantil de maneira lúdica, estimulando a expressividade e a liberdade de movimentação caracteriza o tema Função-Expressão.

Não podemos parar de nos questionar sobre o nosso trabalho. O importante é definir o que se deseja ensinar e a estrada principal que se pretende seguir. Paradas, desvios, ou até mesmo voltar ao início para depois continuar, é normal. Não é a quantidade de erros e acertos que define o bom ou o mau professor. Entramos em sala de aula pelos alunos. Não adianta de nada seguir nessa estrada da educação sozinhos, imaginando que fazemos um bom trabalho quando apresentamos a nós mesmos um planejamento utópico; precisamos seguir nesta estrada na companhia dos alunos. Por isso o roteiro deve ser traçado pensando no seu desenvolvimento e nas suas potencialidades.

Percebo, portanto, os Grandes Temas do Sistema Laban/Bartenieff de Análise de Movimento como os caminhos para conectar conteúdos e ampliar as possibilidades do trabalho de dança com as crianças.

\section{Referências:}

BARTENIEFF, Irmgard. Body Movement: coping with the environment. 1.ed. Nova lorque, Routledge, 2002.

BERTAZZO, Ivaldo. Gesto orientado: reeducação do movimento. São Paulo: Edições SESC, 2014.

BRASIL. Referencial Curricular Nacional para a Educação Infantil. Volume 3. Brasília: MEC/SEF, 1998.

COTTIN, Raphael. Reflections on the shape realm of Laban Movement Analysis (LMA) and how symbols are used to represent it. Supervisão de pesquisa Ângela Loureiro. Tradução Pauline Reeder. 2012.

COX, Laura, STUDD, Karen. Everybody is a body. Indianapolis: Dog Ear Publishing, 2013.

DALBY, John; NEWLOVE, Jean. Laban for all. Nova lorque: Routledge, 2004.

FERNANDES, Ciane. O corpo em movimento: o sistema Laban/Bartenieff na formação e pesquisa em artes cênicas. 2. ed. São Paulo: Annablume, 2006. 


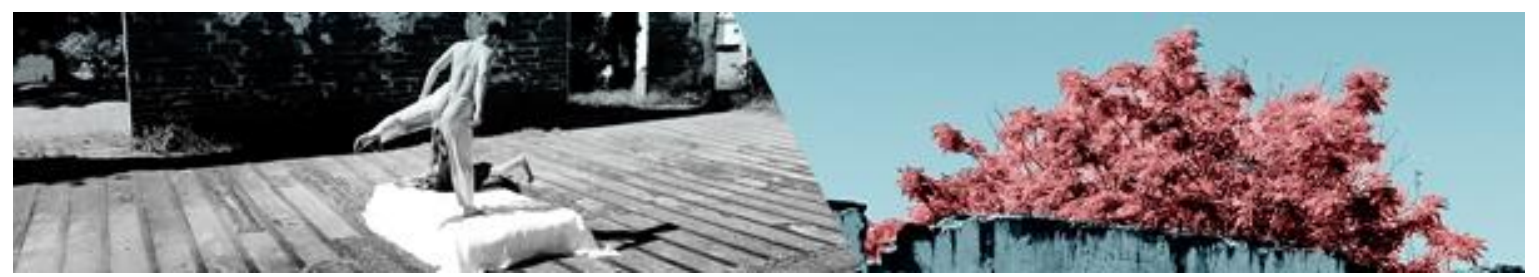

. Criatividade, conexão e integração: uma introdução à obra de Irmgard Bartenieff. In: BOLSANELLO, Débora Pereira (Org.). Em pleno corpo: educação somática, movimento e saúde, 2.ed. Curitiba: Juruá, 2010. p. 34 - 48.

FERREIRA, Ângela. Dança criativa - Uma nova perspectiva do ensino e da criação. In: CALAZANS, Julieta; CASTILHO, Jacyan; GOMES, Simone (Orgs). Dança e Educação em Movimento. 2.ed. São Paulo: Cortez, 2008.

GUIMARÃES, Maria Cláudia Alves. Rudolf Laban: Uma vida dedicada ao movimento. In: MOMMENSOHN, Maria; PETRELLA, Paulo (Orgs.). Reflexões sobre Laban, o mestre do movimento. São Paulo: Summus, 2006. p. 39 - 50.

HACKNEY, Peggy. Making connections: total body integration through Bartenieff Fundamentals. 1.ed. Nova lorque: Routledge, 2002.

LABAN, Rudolf. Domínio do Movimento. 5.ed. São Paulo: Summus, 1978.

LABAN, Rudolf Von; ULLMANN, Lisa. Dança educativa moderna. Ed. corrigida e ampl. São Paulo: Ícone, 1990.

LABAN, Rudolf. In: MARQUES, Isabel A. Ensino da dança hoje: textos e contextos. 2.ed. São Paulo: Cortez, 2001.

MARQUES, Isabel. Dançando na escola. 6.ed. São Paulo: Cortez, 2012.

.Ensino de dança hoje: textos e contextos. 6.ed. São Paulo: Cortez, 2011.

. Linguagem da dança: arte e ensino. 1.ed. São Paulo: Digitexto, 2010.

. De tripé em tripé: o caleidoscópio do ensino de dança. In: BARBOSA, Ana Mae; CUNHA, Fernanda Pereira da (Orgs.). A abordagem triangular no ensino das artes e culturas visuais. São Paulo: Cortez, 2010. p. 52 - 63.

MINISTÉRIO DA EDUCAÇÃO - BRASIL. Base Nacional Comum Curricular. Brasília: MEC, 2018.

MINISTÉRIO DA EDUCAÇÃO - BRASIL. Parâmetros Nacionais de Qualidade da Educação Infantil. Brasília: MEC, 2018.

MIRANDA, Regina. Movimento expressivo. Rio de Janeiro: Funarte, 1979.

. Corpo-espaço: aspectos de uma geofilosofia do corpo em movimento. Rio de Janeiro: 7 Letras, 2008.

MENEZES, Ebenezer Takuno de; SANTOS, Thais Helena dos. Verbete RCN para a Educação Infantil. Dicionário Interativo da Educação Brasileira - Educabrasil. São 


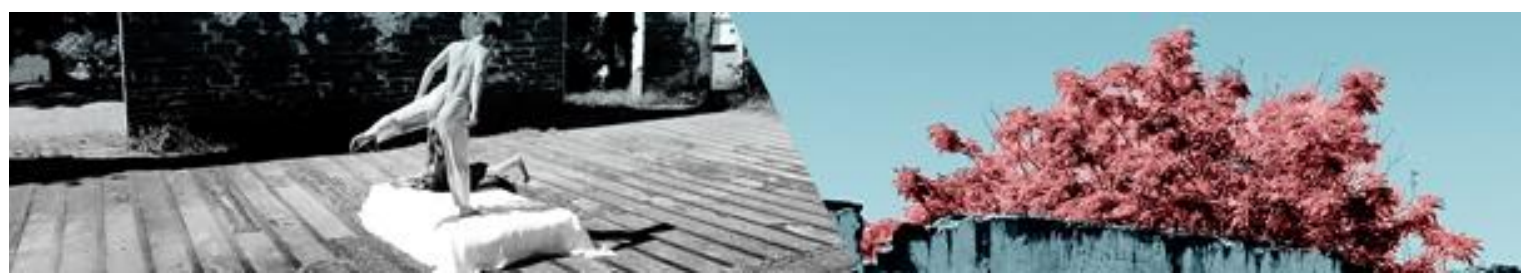

Paulo: Midiamix, 2001. Disponível em: <http://www.educabrasil.com.br/rcn-para-aeducacao-infantil/>. Acesso em: 27 de abr. 2018.

MOMMENSOHN, Maria. Corpo trans-lúcido: uma reflexão sobre a história do corpo em cena. In: MOMMENSOHN, Maria; PETRELLA, Paulo (Orgs.). Reflexões sobre Laban, o mestre do movimento. São Paulo: Summus, 2006. p. 105 - 118.

NEVES, Renata M. S. Dança é para todos. In: MOMMENSOHN, Maria; PETRELLA, Paulo (Orgs.). Reflexões sobre Laban, o mestre do movimento. São Paulo: Summus, 2006. p. $235-242$.

OSSONA, Paulina. A educação pela dança. 4.ed. São Paulo: Summus, 1988.

PETRELLA, Paulo. Prefácio. In: MOMMENSOHN, Maria; PETRELLA, Paulo (Orgs.). Reflexões sobre Laban, o mestre do movimento. São Paulo: Summus, 2006. p. 11 14.

PRESTON-DUNLOP, Valerie Monthland. A handbook for modern educational dance. 1.ed. U.S.A.: Plays Inc., 1980.

RENGEL, Lenira. Fundamentos para análise do movimento expressivo. In: Reflexões sobre Laban, o mestre do movimento. São Paulo: Summus, 2006. p. 121 $-130$.

SILVA, Sonia. O movimento que recria o mundo: um colóquio pedagógico-musical entre Laban e Koellreutter. In: MOMMENSOHN, Maria; PETRELLA, Paulo (Orgs.). Reflexões sobre Laban, o mestre do movimento. São Paulo: Summus, 2006. p. 211 $-222$.

SILVEIRA, Saulo Os princípios e fundamentos corporais Bartenieff como precursores de uma poética inclusiva. In: BOLSANELLO, Débora Pereira (Org.). Em pleno corpo: educação somática, movimento e saúde, 2.ed. Curitiba: Juruá, 2010. p. $49-61$. 